methods described in these documents are designed to enable NGO facilitators to use both livelihood and conservation criteria to select the most appropriate market sectors on which to focus. Guidance is provided on how to engage key market actors, including private sector actors that conservationists may not traditionally interact with and who may not initially be interested in the environmental impacts of their businesses. Tips are provided on how to frame discussions in terms of business interests, such as product quality and sustainability of supply, and how these are related to sustainable use and conservation. Exercises are provided to help empower marginalized producers to have the skills and confidence to negotiate with input and service providers, as well as with traders, and with government agencies whose policies influence the business enabling environment.

A central element of the Participatory Market System Development process is bringing together key market actors to map their current market system, increasing their understanding of the roles of other actors and the importance of communication and information flows along the value chain. Through facilitated discussion of challenges and opportunities these actors can begin to identify simple strategies that they can implement to improve the system for mutual benefit. This process helps build more transparent, fair and trusting relationships between producers and other market actors.

The guidance documents include examples and case studies of how these tools have been applied in a wide range of FFI projects in Kyrgyzstan, Indonesia, Myanmar, Tanzania and other countries. Market sectors addressed include marine fisheries and non-timber forest products, and involve the participation and empowerment of both women and men. In all cases well-governed local natural resource management institutions, whether customary or newly established, have played a vital role in ensuring that local communities benefit from improved livelihoods without overexploiting their natural resource base. Secure tenure, in the form of officially recognized locally managed marine areas or community forests, has been shown to be a major enabling factor in the success of these initiatives. Strong links between support to market system development and conservation outcomes are key to ensuring that this approach incentivizes not just sustainable use but also has positive impacts on wider marine and forest ecosystems.

These newly published documents, together with a previously published Learning Paper, are freely available at faunaflora.org/approaches/livelihoods-governance/sustainableeconomic-opportunities.

HELEN SCHNEIDER (@ orcid.org/0000-0001-8037-2047)

Fauna \& Flora International, Cambridge, UK

E-mail helen.schneider@fauna-flora.org

\section{Concerns about trade in wild finches in Algeria}

Songbird species across the globe suffer from excessive collection for trade. This trade can operate outside regulation and can lead to significant declines in wild populations. Songbirds such as finches are popular pets because of their singing ability, cultural value, and in some cases the social status that owning them can offer. The European goldfinch Carduelis carduelis, serin Serinus serinus and common linnet Linaria cannabina range across Europe, North Africa, the Middle East and East Asia and, although they are categorized as Least Concern by IUCN, they are affected by a range of factors that influence their conservation. The wild populations of serins and linnets are decreasing and, although the European goldfinch is increasing in numbers in some parts of its range, the population in North Africa is experiencing a drastic range reduction. Between 1990 and 2016 the species' distribution declined by $57 \%$ in the region as a result of the songbird trade (Khelifa et al., 2017, Scientific Reports, 7, 1092). From November 2017 to February 2018 we monitored Algeria's most popular classified advertisement website, and from August 2018 to December 2018 we visited 27 cities in Algeria. We searched the markets and pet shops for wild animals in trade. The European goldfinch and serin are included on the list of protected species, prohibiting all trade.

The three species of finch were the most commonly observed birds in markets and pet shops. European goldfinches were offered for sale in 25 of the 27 cities we visited, serins in 13 and common linnets in 11. We observed 3,197 European goldfinches, 295 serins and 162 linnets. In the online trade we found at least 5,480 goldfinches for sale in 394 advertisements. Serins and linnets were not traded online in significant numbers, with only two and one individuals observed, respectively. Despite the illegal nature of these sales, they are conducted openly, and no attempt was made to conceal the birds. Prices for a European goldfinch were USD 18-209, for a serin USD 2-15 and for a common linnet USD 4-13. A small number of birds were reported to be captive bred ( $5 \%$ in online sales), but the vast majority were said to have been taken from the wild. Vendors in every city in which there was significant trade of goldfinches reported that the majority of birds were sourced in Morocco and smuggled across the border.

Pet shops tended to have a small number of birds, averaging five goldfinches per shop. More were sold at the weekly markets (on average 160 goldfinches) that take place on a Friday or Saturday. Large-scale vendors, who store birds in a warehouse and bring them in boxes to the weekly markets, stated that they tend to bring only sufficient birds to sell each week, whereas small-scale vendors return with caged birds on multiple weeks, seeking a good price for a bird of high quality. Based on repeat surveys in a single market in Guelma, we found a minimum of $78 \%$ turnover within 
2 weeks. Extrapolating from this, there could be over 30,000 goldfinches, 7,000 serins and 4,500 linnets sold per year in the 21 weekly markets we visited. The birds sold in the hundreds of pet shops around the country, the weekly markets we did not visit, and those sold online would add substantially to this number.

Vendors reported that goldfinches are becoming increasingly difficult to source from the wild but that there is no lessening of demand. Already, the pressure has shifted from the Algerian to Moroccan populations because of the difficulty in securing sufficient numbers of birds. The illegal songbird trade in Algeria is threatening wild populations of European goldfinches across North Africa and potentially threatening other species of finch. We therefore recommend that the Algerian government enforce its wildlife trade laws to ensure the conservation of these, and other, species.

Daniel Bergin and Vincent NiJMan Oxford Wildlife Trade Research Group, Oxford, UK. E-mail vnijman@brookes.ac.uk

SADEK ATOUSSI Université 8 mai 1945 Guelma, Guelma, Algeria

\section{Evidence to action: research to address illegal wildlife trade}

The Oxford Martin Programme on the Illegal Wildlife Trade (illegalwildlifetrade.net) has launched a key research brief, Evidence to Action: Research to Address Illegal Wildlife Trade (osf.io/preprints/socarxiv/35ndz). This brief, addressed to policy makers and practitioners, outlines areas where research evidence can support effective illegal wildlife trade policy, highlights critical uncertainties where research is required, and emphasizes the need for better design and evaluation of interventions that can help improve the effectiveness of efforts to combat illegal wildlife trade. Tools and expertise to improve the evidence base for national and international illegal wildlife trade policy already exist but are underutilized. Tapping into these resources could produce substantive benefits for wildlife conservation and associated sectors, enabling governments to fulfill their obligations under the Sustainable Development Goals and international biodiversity conventions. This could be achieved through enhanced funding support for intersectoral research collaborations, engaging researchers in priority setting and programme design, increasing developing country research capacity and engaging researchers and community voices in policy processes.

The Evidence to Action brief is the first of a new set of tools and guidance for researchers and practitioners. The latest addition is a brief reviewing the scale of Darknet Usage in the Illegal Wildlife Trade (osf.io/preprints/ socarxiv/fgrgd), which includes recommendations for researchers and policymakers. The darknet is a network of websites that can be accessed only via special software that hides the details of the user's connection, and allows websites to be hosted without revealing their location or operator. Large-scale darknet marketplaces exist for illegal drugs, firearms, hacking tools, stolen identity documents, and a wide variety of other illicit goods. However, the darknet has not, to date, proven to be an attractive platform for the buying and selling of illegal wildlife products (see also Oryx, 51, 393-394). Despite this, it provides a marketplace of last resort that becomes increasingly attractive over other, more accessible, online services as law enforcement and platform operators enforce policies against trading in illegal wildlife products. This makes the ongoing study of darknet markets an important avenue for research as other policies against online illegal wildlife trading emerge.

LAURE CUGNIERE (๑ orcid.org/0000-0002-4753-593X) Department of Zoology, University of Oxford, Oxford, UK E-mail laure.cugniere@zoo.ox.ac.uk

JOSS WRIGHT (๑ orcid.org/0000-0001-5237-3309) Oxford Internet Institute, University of Oxford, Oxford, UK

E.J. MILNER-GULLAND (৫ orcid.org/0000-0003-0324-2710)
Department of Zoology, University of Oxford, Oxford, UK

\section{Halting the release of the pangolin Manis javanica in China}

As global travel and trade increase, so has the numbers of species spreading beyond their natural ranges. Introduction of alien species, intentionally or unintentionally, as a result of human activities may lead to the extinction of native species via interbreeding, predation, resource competition or the spread of disease. Pangolins are widely trafficked (S. Heinrich et al., 2017, The Global Trafficking of Pangolins: a Comprehensive Summary of Seizures and Trafficking Routes from 2010-2015, TRAFFIC South-east Asia, Selangor, Malaysia), and with the Chinese government improving wildlife protection and strengthening law enforcement the release of confiscated pangolins by law enforcement departments is increasing. There have been at least 10 cases of the release of confiscated pangolins into the wild in China since 2016, including one case each in October 2016, January, July and September 2017, May, June and August 2018, and three cases in July 2018 (mp.weixin.qq.com/s/zWQ27feivjiO4bBjZPKvFQ). In at least five cases the release was of Manis javanica, which is native to South-east Asia, including cases in Zhanjiang city, Hengyang city, Wenshan Zhuang and Miao Autonomous Prefecture, and Xishuangbanna Dai Autonomous Prefecture. 